\section{ECONOMICS}

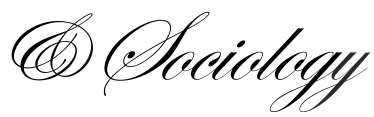

\title{
RELATIVE CONSUMPTION WITH MULTIPLE REFERENCE POINTS UNDER UNCERTAINTY
}

\author{
Kármen Kovács \\ University of Pécs, Faculty of \\ Business and Economics \\ Pécs, Hungary \\ E-mail: \\ kovacs.karmen@,k.tk.pte.hu \\ ORCID 0000-0002-5612-2037
}

Received: November, 2019

1st Revision: September, 2020

Accepted: December, 2020

DOI: $10.14254 / 2071-$

789X.2020/13-4/4

\author{
JEL Classification: D11, \\ D91
}

\begin{abstract}
According to the behavioural economic perspective, an individual's consumer utility derives not only from their absolute consumption but also how much they consume relative to others, that is, relative consumption matters. The purpose of this paper is to study relative consumption by focusing on social comparison, multiple reference points, and uncertainty related to the expectations about others' future consumption. The model presented reflects the dynamics and intertemporal effects of relative consumption concerning consumer utility. The purpose of the model is to describe, by applying theoretical comparative analysis, how an individual's consumer utility derived from relative consumption can change when their social reference points' future absolute consumption level is uncertain. When an individual wants to improve or at least sustain their relative consumption in the future, they have to take into account and estimate the future absolute consumption levels of the persons belonging to their reference group. However, neighbours' future consumption is usually uncertain, thus, the likely outcomes are illustrated with various cases. The study concludes that higher absolute consumption level not necessarily provides higher consumer utility when positional concerns matter. Further, despite investments in positional goods, the misprediction of others' future absolute consumption level can result in lower social standing.
\end{abstract}

Keywords: relative consumption, social comparison, social position, reference points, consumer utility model.

\section{Introduction}

According to the neoclassical economic theory, an individual's consumer utility is independent of others and depends only on the absolute level of his own consumption. However, behavioural economics can describe and explain consumption and its relations in a more realistic and sophisticated way as it integrates psychological insights and experimental findings into economic theory. Under this approach, an individual's utility derives not only from the absolute level of his consumption but also how much his consumes relative to others, that is, relative consumption is the determinant. It means that positional concerns do matter. People strive not only to enhance their utility through increasing consumption but to own more 
than others. It is confirmed by several empirical research (Alpizar, Carlsson, \& JohanssonStenman, 2005; Birdal \& Ongan, 2016; Carlsson, Johansson-Stenman, \& Martinsson, 2007; Grolleau \& Saïd, 2008; Solnick \& Hemenway, 2005).

The fact that relative consumption is important for individuals has been realised and studied by several outstanding scholars such as Smith (1776/1976), Keynes (1936/1996), Veblen (1899/1979), Pigou (1903, 1913), Galbraith (1958) and Scitovsky (1976). The investigation of Solnick and Hemenway (1998) points out that higher relative consumption is more important for individuals than the higher absolute consumption level. In their survey, the respondents can choose which of two societies they would like to live in. In society, they have more than others, and consequently, better relative standing can be gained, or in a community where the respondents have fewer goods than others but the absolute level of their consumption is higher as compared to their consumption in the first society. According to the empirical results, relative higher standing is preferred by most of the individuals. The study of Solnick and Hemenway (1998) has been carried out several times in various cultures and circumstances (Alpizar et al., 2005; Carlsson et al., 2007; Grolleau, Mzoughi, \& Saïd, 2012; Grolleau \& Saïd, 2008; Solnick \& Hemenway, 2005; Solnick, Hong, \& Hemenway, 2007). All the investigation confirms that the majority of people prefer a positional rather than an absolute state ${ }^{1}$.

Solnick and Hemenway (2005) verify that the role of goods is different in relative consumption; some of them are more positional than the others. Clothing and house size are more relevant than health and safety. Alpizar et al. (2005) point out that in several relevant papers on relative consumption (e.g. Frank, 1985b; Hirsch, 1976), it is assumed that some goods, such as car, house and jewellery, have considerable role in positional rivalry but other goods, like bread and insurance, are less positional. However, Alpizar et al.'s (2005) empirical findings indicate that the degree of positionality of some goods, like insurance, is more significant than scholars usually assume it ${ }^{2}$. Due to the inconsistency, we do not contrast goods with each other in our study below here.

The relevance and the effect of relative consumption have increased since more and more goods, and fields of life become positional. Bronner and de Hoog (2018) argue that nowadays consumers consider not only physical goods during social comparison but also immaterial experiences (e.g., holidays) as they have become more socially visible due to the effects of social media. Similarly, Yang and Mattila (2017) point out that individuals can observe others' consumption of less visible goods (e.g., household assets) and experimental purchases (e.g., wellness services), again, due to the power of social media. Further, more and more frequent launching of new products and innovations induce individuals partly to gain higher relative standing by possessing them. This phenomenon also contributes to the increased intensity and importance of social comparison that result in a more vigorous rivalry for social standing.

The purpose of this paper is to study relative consumption by focusing on social comparison, multiple reference points, and uncertainty related to the expectations about others' future consumption. The model presented here may offer a new framework for the investigation of relative consumption. It assists in interpreting the potential change of consumer utility derived from relative consumption when neighbours' future consumption is uncertain. It is essential since the outcome of an individual's decision about his absolute consumption level is uncertain. That is, one cannot be sure how his relative social position changes since people are interdependent and positional concerns do matter.

\footnotetext{
${ }^{1}$ However, Solnick et al. (2007) confirm with empirical findings that cultural characteristics affect considerably how positional concerns are manifested in society.

${ }^{2}$ Alpizar et al. (2005) also discover that the absolute consumption of positional goods, like car or house, is also relevant for individuals despite literature underlines their role in relative consumption and social rivalry.
} 
The literature review section uncovers the background and the manifestation of relative consumption. It describes the core and different forms of social comparison, points out the role and the potential relations of various reference points, highlights the relevance of uncertainty, primarily related to expectations about others' future consumption, and mentions some relations to financial position. The core section of the paper presents the model of relative consumption with multiple reference points under uncertainty. Some cases are also provided to illustrate the uncertain outcomes when relative consumption does matter.

\section{Literature review}

Positional concerns are relevant for the members of all social classes since individuals can gain esteem and admiration through higher relative standing. However, according to Leguizamon's (2016) findings, it is the middle class that tends to invest the most to enhance relative position. Several emotions but primarily envy has a considerable role during social comparison and in improving relative consumption. Solnick and Hemenway (1998) argue that envy is a driver of positional concerns. Van de Ven, Zeelenberg and Pieters (2009) claim and provide empirical evidence that two types of envy are qualitatively diverse. Benign envy inspires individuals to improve their own standings. However, in the case of malicious envy, individuals are motivated to hurt others who are perceived to be admirable. Both of them can manifest during the rivalry for social position. Celse, Galia and Max (2017) investigate the effect of (basic) emotions on the expression of positional concerns. Their experimental laboratory research findings indicate that negative emotions such as anger do not induce individuals to "keep up with the Joneses". However, positive emotions like joy contribute considerably to improve their relative standing.

Although emotions have a considerable role in striving for improving relative standing, Frank (1985a) states that positional concerns can be considered rational since higher position can contribute to achieving several purposes. For example, a person with higher status can be more influential socially. Ball, Eckel, Grossman, and Zame (2001) also claim that social standing is relevant as it influences resource allocation among economic actors.

Relative consumption also can be explained according to the social comparison theory described by Festinger (1954). The basic assumption of this theory is that individuals would like to assess themselves accurately. Thus, they compare themselves with others. Individuals demand social comparison especially in uncertain situations when their self-evaluation becomes more relevant for them, and it can be precisely defined by reference points. In current communication technological and cultural environments, individuals compare their consumption to others' easier and more often. Nowadays, not only material goods that are closely related to individuals' appearance (e.g. cars, clothes, fashion accessories, smartphones) are relevant in relative consumption. Yang and Mattila (2017) and Bronner and de Hoog (2018) suggest that less visible goods (e.g. furniture) and immaterial experiences (e.g. participating in free-time programmes) have a growing role in social comparison since they have become more observable due to the usage and impact of social media. Garcia, Tor, and Schiff (2013) demonstrate a social comparison model by taking into consideration competitive behaviour. They define individual factors that are different for each individual (e.g. rivals' likeness) and situational variables that influence individuals in similar positions (e.g. closeness to an ideal). Hopkins and Kornienko (2009) highlight that the most important players for individuals who strive to improve their positions in relative consumption are the persons around them, such as friends, colleagues, relatives or members of their sports teams. Thus, social comparison and rivalry occur primarily with them.

The comparison can be considered as the difference or the ratio between individual consumption and others' consumption (Clark \& Oswald, 1998). This approach is reflected in 
the cardinal status (Bilancini \& Boncinelli, 2008). Further, rank-based comparison (Hopkins \& Kornienko, 2009) is also possible. It is expressed as the ordinal status that means "the rank in the distribution of the possession of the status-bearing good or asset" (Bilancini \& Boncinelli, 2008, p.17). The perceived relative consumption or believed social standing is integrated into consumer utility functions. Akerlof (1997) incorporates difference comparison, Duesenberry (1949) includes ratio comparison, and Frank (1985b) reflects ordinal status in the consumer utility function. Beside Bilancini and Boncinelli (2008) highlight the difference between cardinal and ordinal status, they also demonstrate that research findings can be various depending on which status interpretation is applied in models. Wang, Cheng, and Smyth (2019) conclude that an individual's ordinal standing in his reference group regarding consumption influences his happiness significantly. However, it is important to notice that an individual's ordinal status can remain stable even though he spends less on consumption and the poorer in his reference group consume more, that is, the cardinal difference decreases between them. Thus, a lower consumption level can result in the same level of happiness when the ordinal status does not change.

From the perspective of self-assessment and consumer utility, it is important to emphasise that Bucciol, Cavasso, and Zarri (2015) distinguish objectively measured social status and subjective social status. The objective index is calculated based on explanatory variables such as the degree of education, income level, financial and real wealth. However, subjective social status is determined by an individual's self-assessment of his own position in the social hierarchy. The two types of status measure are positively but only moderately correlated with each other. It is the subjective social status that is perceived by people and can impress them directly. Some of the factors of the objective position are usually not known for others. Consequently, subjective social status inspires individuals to enhance their relative consumption level. Nowadays, it is developing based on more and more information as the social comparison is not restricted to personal observation but the perception of one's social standing occurs by the impact of an increasing number of communication channels. Thus, the subjective social status becomes a more complex measure.

Kahneman and Tversky (1984) argue that social comparison effects reference points. Consequently, perceived social standing influences individuals' decision. However, individuals' goals (Heath, Larrick, \& Wu, 1999) and expectations (Köszegi \& Rabin, 2009) are also possible relevant reference points. They are related to the future and include a kind of uncertainty at the same time since an individual usually cannot be sure that he achieves his purposes, and future circumstances turn out according to his expectations. Thus, an individual can feel success or failure based on the outcome of his decision under uncertainty. These are essential in the case of positional concerns and relative consumption.

Most of the investigations take into consideration only one reference point. However, there are usually more reference points influencing decision-making simultaneously, especially in uncertain or risky situations ${ }^{3}$. The various reference points can have a convergent or divergent effect on behaviour. It is confirmed by empirical evidence (Koop \& Johnson, 2012; Ordóñez, Connolly, \& Coughlan, 2000).

Kahneman (1992) states that when individuals have more reference points they can compare the result of their decision with each reference point separately, or they can integrate the various reference points into a single reference point, and overall assessment is conducted related to this. The experimental findings of Ordóñez et al. (2000) show that individuals consider various reference points separately. Segregation is due to the lack or difficulty of

\footnotetext{
${ }^{3}$ Uncertainty and risk are distinguished according to Knight (1921). Choice under uncertainty occurs when the probabilities of the potential outcomes are unknown. However, when the probabilities of the alternatives are known, an individual faces a decision under risk.
} 
comparability of reference points. When an individual's each relevant social reference point possesses a positional good that is unique or very different from others' but determines the social standing, they are considered separately. Integration is more likely when reference points are comparable (Ordóñez et al., 2000). If an individual evaluates others' cars before purchasing one for himself, he can integrate them to find the best choice.

Wang and Johnson (2012) suggest a tri-reference point theory for risky decision making where status quo, goal and minimum requirement are reference points simultaneously. According to Rayo and Becker's (2007) evolutionary model of happiness an individual has three reference points since he compares his own current consumption to his own past consumption, others' past consumption and others' current consumption. Similarly, Aronsson and Johansson-Stenman (2014) distinguish three factors that influence or change consumption over time, (internal) habit formation, "keeping up with the Joneses" and "catching up with the Joneses" (external habit formation). As people strive to improve their social position, certain superiors are considered as reference points. Grolleau and Saïd (2008, p.1153) provide thorough explanation for upward-looking comparison or, in other words, "keep up with the richer Joneses": "poor people can be more interested in consuming positional goods because each dollar invested in such consumption generates a higher marginal return in terms of status benefits compared to what it gives to a rich person".

Even though based on a different perspective, Lu, Xie, Wang, and Tang (2015) also suggest multiple reference points. Beside social reference points, they consider an individual's present financial position as a financial reference point. Lu et al. (2015) state that individuals think about the financial reference point(s) firstly, and then social reference points are considered. Thus, based on an evolutionary perspective, the safety-first principle is valid (Wang \& Johnson, 2012). Individuals are in safe if they can achieve their financial goals. When social reference points are reflected, individuals take into consideration not only social standing but how the social standing can counterbalance their financial position which is judged by the financial reference points. (Due to this the psychological process the case of multiple reference points is different than there is a single reference point.) Consequently, in this perspective, utility depending on relative consumption is influenced by both social and financial reference points (Lu et al., 2015).

In general, individuals' main goal is to improve relative consumption without their financial position is getting worse. However, people are interdependent since an individual's choice, and consumer utility are influenced by his social reference points, and he also has an effect on others' preferences and payoffs. As Hopkins and Kornienko (2004) highlight, to achieve optimal consumption, others' consumption decisions have to be predicted appropriately. It means expectations about others' future consumption and their impact have a critical role in the change of an individual's relative standing and the consumer utility level gained by him. These circumstances reflect implicitly that an individual's consumer decisionmaking occurs under uncertainty with multiple reference points. However, there is a research gap on this issue. The model and the related cases presented in this paper seek to achieve the description and the analysis of the problem mentioned above. Further, Rohde and Rohde (2011) add that an individual's choice also depends on the uncertainty other consumers come up against.

These relations are linked to the fact that an individual's reference points affect the degree of his risk aversion (Rustichini, DeYoung, Anderson, \& Burks, 2016). In the case of relative consumption, an individual considers how much to invest into positional goods, taking

\footnotetext{
${ }^{4}$ We use the phrase "keeping up with the Joneses" in the sense that an individual's utility is influenced by how his current consumption is related to others' current consumption. While 'catching up with the Joneses' expresses that present utility partly depends on how an individual's current consumption is related to others' former consumption.
} 
into account his financial position, his aspirations for improving social standing and consumer utility level and his expectations for others' choice and the impact of his own decision. As this is an uncertain decision situation, an individual cannot be sure that the costs of investment will be returned, that is, he can achieve a higher relative social position and an increase in his consumer utility level. During the economic crisis started in 2008, several individuals and households have become indebtedness due to an unsuccessful attempt to improve relative standing by investing into real estates and other durable goods since they underestimated the uncertainty of their choice, especially compared to their financial position. In recent years, individuals often overspend on positional goods again to "keep up with the Joneses" that is largely due to the new and easier available financial instruments.

Hirsch (1976) claims if an individual's income rises, a growing share of his income is spent on positional goods. Despite the marginal utility of consumption decreases, more consumption is needed to achieve a higher social position. Brekke, Howarth, and Nyborg (2003) conclude that Hirsch's hypothesis is valid if social status depends on the difference between an individual's consumption and the average consumption of the society. However, if the social position is related to the ratio of individual and average consumption, Hirsch's hypothesis is valid only when the position and non-positional goods are imperfect substitutes.

By applying a game theoretical approach, Hopkins and Kornienko (2009) underline that the Nash equilibrium of the positional game is inefficient in the sense that each player's expenditure for positional goods is higher than the optimal level, but overspending does not generate the increase of relative position. Further, they claim that greater equality in society induces spending on positional goods since individuals possessing such goods can enhance social position easier due to improved relative consumption. Similarly, Frank (2005) states that models including positional concerns anticipate an equilibrium where individuals' spend too much on positional goods, and a relatively low amount is allocated on normal goods.

To sum up, it can be stated that relative consumption is driven by positional concerns and social comparison which have several forms. Beside social reference points, the financial position also influences considerably an individual's choice who strives to improve his relative standing. As there is interdependence among individuals and rivalry for social position is a never-ending story, the decision-making related to relative consumption is an intertemporal choice. Due to this fact, uncertainty has a core role in both social and financial sense in the case of relative consumption.

\section{Modelling relative consumption with multiple reference points under uncertainty}

\subsection{Framework and assumptions}

The model presented in this section focuses on relative consumption with multiple reference points. The purpose of the model is to describe the potential change of consumer utility derived from relative consumption under neighbours' uncertain future absolute consumption level. Further, to point out that an individual's choice about his absolute consumption that is determined according to his expectations about neighbours' future absolute consumption level does not necessarily result in higher relative consumption although he strives for that. Both increased and decreased absolute consumption level can be justified by taking into consideration his reference points; however, the outcome of his choice is uncertain and can even result in lower relative standing.

In this model, consumer utility function only depends on relative consumption, that is, how much he consumes relative to others and his past absolute consumption level. Although relative consumption is based on absolute consumption level, the intrinsic value of consumption 
does not influence the utility level directly. Consumer utility function does not include the individual's financial position or financial reference points since utility comes from consumption but not from financial position or savings.

We distinguish real and expected utility. The real one means the realised utility level in a certain time period when all the variables are known. However, the expected utility is partly based on future expectations about others' absolute consumption, so the consumer choice entails uncertain outcome, or in other words, future relative standing.

We assume three sequential time periods which are past $(t-1)$, present $(t)$ and future $(t+1)$. According to our approach, this is a short run. Consequently, we assume that an individual attaches the same importance to the comparison with a reference point over time. (However, in the long run, the weights can modify.) Social comparison occurs in a cardinal sense. We study both difference and ratio comparison. Further, we assume that an individual strives to improve or at least sustain his relative consumption over time, that is, he does not want his social position to weaken.

In accordance with Rayo and Becker (2007) and Aronsson and Johansson-Stenman (2014), let individual $i$ has three social reference points. Thus, he compares his current consumption with others' present consumption, others' past consumption and his own past consumption. We assume that the members of the reference group are neighbours as Hopkins and Kornienko (2009) also suggest ${ }^{5}$. Let individual $i$ makes comparisons with discrete individuals ${ }^{6}$ since social interactions occur in a small group (e.g. family, working place, sports team) in everyday life and individual social comparisons have a considerable effect on selfevaluation (Alicke, 2007) ${ }^{7}$. Individual $i$ may give various importances to comparisons with persons around him. If we assume that there are $n$ neighbours, individual $i$ 's real consumer utility derived from relative consumption in time period $t$ can be expressed as

$$
U_{i_{t_{r}}=\alpha} \alpha\left(c_{i_{t_{r}}-} c_{i_{t-1}}\right)+\sum_{j=1}^{n} \beta_{i j}\left(c_{i_{t_{r}}-} c_{j_{t_{r}}}\right)+\sum_{j=1}^{n} \gamma_{i j}\left(c_{i_{t_{r}}-c_{j_{t-1 r}}}\right)
$$

when the social comparison is implemented based on the difference or as

$$
U_{i_{t_{r}}=} \alpha \frac{c_{i_{t_{r}}}}{c_{i_{t-1 r}}}+\sum_{j=1}^{n} \beta_{i j} \frac{c_{i_{t_{r}}}}{c_{j_{t_{r}}}}+\sum_{j=1}^{n} \gamma_{i j} \frac{c_{i_{t_{r}}}}{c_{j_{t-1 r}}}
$$

when the social comparison occurs according to the ratio where

$c_{i_{t_{r}}}$ is individual $i$ 's real absolute consumption in time period $t$

$c_{i_{t-1 r}}$ is individual $i$ 's real absolute consumption in time period $t-1$

$c_{j_{t_{r}}}$ is neighbour $j$ 's real absolute consumption in time period $t$

$c_{j_{t-1 r}}$ is neighbour $j$ 's real absolute consumption in time period $t-1$

$\alpha$ parameter expressing what importance individual $i$ attaches to (internal) habit formation, $0 \leq$ $\alpha \leq 1$

\footnotetext{
${ }^{5}$ Several models (e.g. Akerlof, 1997; Duesenberry, 1949; Goerke, 2013) assume implicitly or explicitly that an individual compares his consumption to all members of the society. Consequently, the average consumption of others is integrated into the individual consumer utility function. However, this approach is unrealistic. Thus, we consider only neighbours as reference points.

${ }^{6}$ It is consistent with social comparison theory (Festinger, 1954) which states comparisons occur with single individuals.

${ }^{7}$ Alicke (2007) points out that aggregate comparison has relevance when norms or typical features form the core of social comparison.
} 
$\beta_{i j}$ parameter meaning what importance individual $i$ attaches to neighbour $j$ 's current real absolute consumption during the social comparison, $0 \leq \beta_{i j} \leq 1$

$\gamma_{i j}$ parameter denoting what importance individual $i$ attaches to neighbour $j$ 's past real absolute consumption during the social comparison, $0 \leq \gamma_{i j} \leq 1$.

If we assumed that individual $i$ strives to maximise his utility level, we would get for the first-order condition according to (1) and (2) that

$$
\frac{\partial U_{i_{t_{r}}}}{\partial c_{i_{t_{r}}}}=\alpha+\sum_{j=1}^{n} \beta_{i j}+\sum_{j=1}^{n} \gamma_{i j} \neq 0
$$

and

$$
\frac{\partial U_{i_{t_{r}}}}{\partial c_{i_{t_{r}}}}=\frac{\alpha}{c_{i_{t-1}}}+\sum_{j=1}^{n} \beta_{i j} \frac{1}{c_{j_{t_{r}}}}+\sum_{j=1}^{n} \gamma_{i j} \frac{1}{c_{j_{t-1 r}}} \neq 0
$$

as all of the parameters cannot be 0 simultaneously since this would mean that relative consumption is irrelevant for individual $i$, that is utility derived from relative consumption is 0 . Consequently, the optimal level of $c_{i_{t_{r}}}$, which would ensure utility maximisation for individual $i$ cannot be determined. In other words, if individual $i$ would strive to maximise his utility, he could not calculate the required additional consumption level compared to others. However, we can state that the greater $c_{i_{t_{r}}}$ is, the higher $U_{i_{t_{r}}}$ is since marginal utility is always positive.

According to this interpretation, we argue that individual $i$ is not a maximiser but a satisficer ${ }^{8}$. This is consistent with the cardinal social comparison in the sense, that it is not assumed he wants to be the best one among others but to achieve a 'good enough' consumption level and position relative to others. In a behavioural economic approach, the assumption, individual $i$ is a satisficer, is justified since Schwartz et al. (2002) provide evidence that consumers are different how much they strive to achieve an optimal choice.

\subsection{The model}

In the case of aspiration for higher relative consumption and social position, several purchasing situations can be considered as an intertemporal choice. When individual $i$ wants to improve or at least sustain his future relative consumption, he has to take into account and estimate the future absolute consumption levels of the persons belonging to his reference group. However, the neighbours' future consumption is usually unknown or uncertain from the viewpoint of individual $i$. (They also take into consideration others' anticipated future consumption when they make a decision about their consumption level.) As beside own current consumption and present others' consumption, others' future consumption is the third reference point; the future consumer utility level is also uncertain. It depends on individual i's expectations about neighbours' future absolute consumption and how he determines his own real future consumption compared to them. If we assume that individual $i$ determines his future absolute consumption level in the current period, individual $i$ 's expected consumer utility derived from relative consumption in time period $t+1$ can be expressed as

\footnotetext{
${ }^{8}$ Individuals who try to choose the best option are called maximisers, while individuals who satisfied with decisions that are 'good enough' are satisficers (Schwartz et al., 2002). Weaver, Daniloski, Schwarz, and Cottone (2015) point out that Simon (1956) who originally described these concepts, distinguished maximisers and satisficers based other their aspiration level. However, Schwartz et al. (2002) establish that maximisers and satisficers vary from each other not only in their aspiration level, but how they interpret 'best' decision.
} 


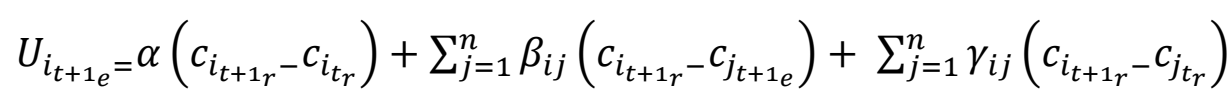

when the social comparison is implemented based on the difference or as

$$
U_{i_{t+1} e}=\alpha \frac{c_{i_{t+1 r}}}{c_{i_{t_{r}}}}+\sum_{j=1}^{n} \beta_{i j} \frac{c_{i_{t+1 r}}}{c_{j_{t+1}}}+\sum_{j=1}^{n} \gamma_{i j} \frac{c_{i_{t+1 r}}}{c_{j_{t_{r}}}}
$$

when the social comparison occurs according to the ratio.

Furthermore, individual $i$ 's real consumer utility derived from relative consumption in time period $t+1$ can be expressed as

$$
U_{i_{t+1_{r}}} \alpha\left(c_{i_{t+1_{r}}}-c_{i_{t_{r}}}\right)+\sum_{j=1}^{n} \beta_{i j}\left(c_{i_{t+1_{r}}-} c_{j_{t+1_{r}}}\right)+\sum_{j=1}^{n} \gamma_{i j}\left(c_{i_{t+1_{r}}}-c_{j_{t_{r}}}\right)
$$

in the case of difference comparison or as

$$
U_{i_{t+1 r}}=\alpha \frac{c_{i_{t+1 r}}}{c_{i_{t_{r}}}}+\sum_{j=1}^{n} \beta_{i j} \frac{c_{i_{t+1 r}}}{c_{j_{t+1 r}}}+\sum_{j=1}^{n} \gamma_{i j} \frac{c_{i_{t+1 r}}}{c_{j_{t_{r}}}}
$$

in the case of ratio comparison where

$c_{i_{t_{r}}}$ is individual $i$ 's real absolute consumption in time period $t$

$c_{i_{t+1} r}$ is individual $i$ 's real absolute consumption in time period $t+1$

$c_{j_{t+1}}$ is neighbour $j$ 's expected absolute consumption in time period $t+1$

$c_{j_{t+1}}$ is neighbour $j$ 's expected absolute consumption in time period $t+1$

$c_{j_{t_{r}}}$ is neighbour $j$ 's real absolute consumption in time period $t$

$\alpha$ parameter expressing what importance individual $i$ attaches to (internal) habit formation, $0 \leq$ $\alpha \leq 1$

$\beta_{i j}$ parameter meaning what importance individual $i$ attaches to neighbour $j$ 's future absolute consumption during the social comparison, $0 \leq \beta_{i j} \leq 1$

$\gamma_{i j}$ parameter denoting what importance individual $i$ attaches to neighbour $j$ 's present real absolute consumption during the social comparison, $0 \leq \gamma_{i j} \leq 1$.

The only difference between $U_{i_{t+1} e}$ and $U_{i_{t+1 r}}$ is that the future reference points are expected ones in $U_{i_{t+1} e}$ but real ones in $U_{i_{t+1}}$. However, this has important consequences.

1. If $U_{i_{t+1} e}=U_{i_{t+1}}$, individual $i$ 's expectations about neighbours' future absolute consumption are correct.

2. If $U_{i_{t+1_{e}}}>U_{i_{t+1}}$, this is a failure for individual $i$ derived from his general underestimation of neighbours' absolute consumption levels in time period $t+1$. Individual $i$ achieves a lower relative consumption in time period $t+1$ than he expected.

3. If $U_{i_{t+1_{e}}}<U_{i_{t+1}}$, this is a success for individual $i$ derived from his general overestimation of neighbours' absolute consumption levels in time period $t+1$. Individual $i$ achieves a higher relative consumption in time period $t+1$ than he expected.

As mentioned above, we assume that individual $i$ strives to improve or at least sustain his relative consumption over time, thus

$$
U_{i_{t_{r}}} \leq U_{i_{t+1 e}}
$$


(9) reflects that individual $i$ chooses the level of his absolute consumption for time period $t+1$ by taking into account others' expected absolute consumption so that he can achieve the utility he realised in time period $t$. However, as it is uncertain what absolute consumption level neighbours choose in time period $t+1$, and consequently $U_{i_{t+1} e}$ is not necessarily equal with $U_{i_{t+1} r}$, it is worth to compare the real utility levels in time periods $t$ and $t+1$.

1. If $U_{i_{t_{r}}}=U_{i_{t+1}}$, individual $i$ can sustain his relative consumption and social position.

2. If $U_{i_{t_{r}}}>U_{i_{t+1}}$, individual $i$ achieves a lower relative consumption in time period $t+1$ compared to $t$, thus his social position diminishes.

3. If $U_{i_{t_{r}}}<U_{i_{t+1}}$, individual $i$ has been successful to improve his social standing through higher relative consumption.

Graph 1 synthesises and presents the abovementioned relations between $U_{i_{t_{r}}}, U_{i_{t+1_{r}}}$ and $U_{i_{t+1} e}$. Three various situations are demonstrated. We assume that $U_{i_{t_{r}}}<U_{i_{t+1} e}$ since individual $i$ wants to improve his relative consumption and that the levels of both $U_{i_{t_{r}}}$ and $U_{i_{t+1}}$ are the same in all three cases. Graph $1 a$ reflects the situation when $U_{i_{t_{r}}}<U_{i_{t+1_{e}}}<U_{i_{t+1}}$. Individual $i$ gains additional utility in time period $t+1$ due to overestimation of others' absolute consumption levels, and this reflects an increase in relative consumption compared to time period $t$ at the same time. According to Graph 1b, $U_{i_{t_{r}}}<U_{i_{t+1} r}<U_{i_{t+1} e}$. On the one hand, the real utility is lower than the expected one in time period $t+1$ due to the underestimation of neighbours' absolute consumption levels. However, individual $i$ can achieve a higher relative consumption in time period $t+1$ compared to $t$. Graph $1 c$ shows the worst situation for individual $i$ as $U_{i_{t+1 r}}<U_{i_{t_{r}}}<U_{i_{t+1}}$. Individual $i$ realises less utility in time period $t+1$ than he expected due to incorrect expectations about others' absolute consumption. A proportion of the lost utility also indicates the lower relative consumption compared to period $t$.
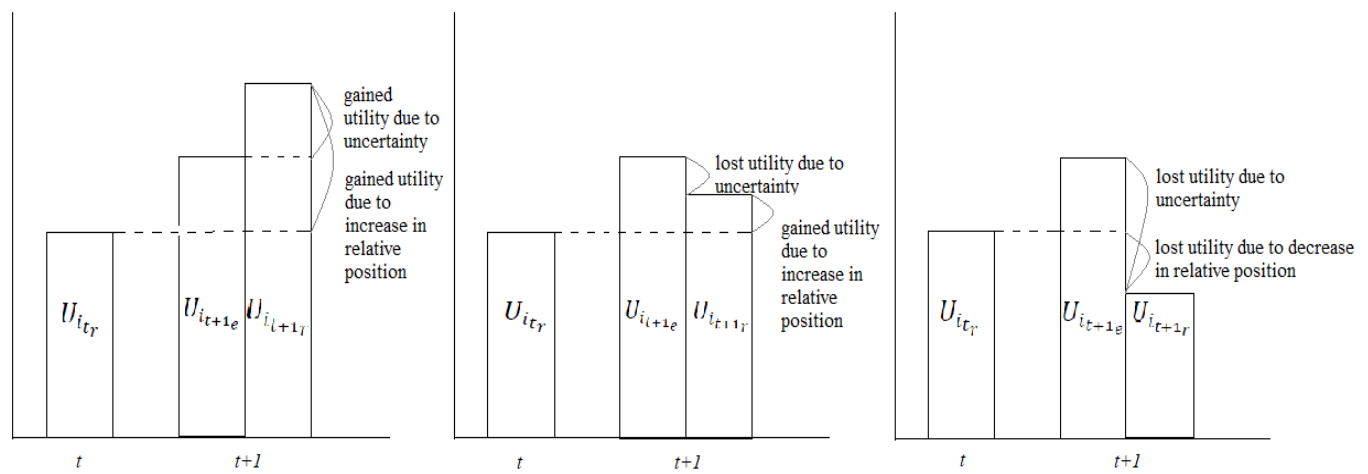

Graph 1a, 1b and 1c Gained vs lost utility due to incorrect expectations Source: own compilation

Consumer utility derived from relative consumption is a function of individual $i$ 's absolute consumption, his neighbours' absolute consumption and what importance he attaches to his reference points during the comparison. This means individual $i$ makes a decision only about his absolute consumption level when he would like to sustain or improve his relative position in the future. However, consumption has to be financed by individual $i$ and the change in absolute consumption level from time period $t$ to $t+1$ influences his financial position. If individual $i$ increases his absolute consumption level to improve his relative position, his consumption expenditures rise, and thus his financial position weakens. However, he cannot be 
sure that the investment into the additional consumption will be recovered since others' absolute consumption is uncertain for him, and thus his relative consumption and the utility coming from that can even decrease. Consequently, despite his higher absolute consumption level, lower relative consumption and utility level can be realised due to his underestimation of others' absolute consumption. It results in a lower social standing. Further, it is worth to highlight that in this situation individual $i$ may perceive his financial position weakened considerably since he cannot achieve a higher relative consumption despite investment into additional consumption. Further, he needs additional resources to regain at least his former relative position.

It is also possible that individual $i$ does not change his absolute consumption level from time period $t$ to $t+1$ since he expects others' do not modify or decrease their absolute consumption level, and thus he can sustain or improve his relative consumption. In this case, his financial position is stable. If his expectations are correct, he can sustain or enhance his social standing. However, if neighbours increase their absolute consumption, individual $i$ 's relative consumption and the utility coming from that diminish.

Individual $i$ can be encouraged in decreasing his absolute consumption if he believes his neighbours decrease their absolute consumption from time period $t$ to $t+1$. (This can occur during a recession.). As his consumption expenditure reduces, his financial position strengthens. Individual $i$ 's real relative consumption depends on how much others reduce their absolute consumption in time period $t+1$ compared to him. If neighbours decrease it by more than individual $i$, he achieves a higher relative consumption. However, if he overestimates the decrease of others' absolute consumption or they sustain or even increase that, his relative standing declines due to his incorrect expectations.

To synthesise and organise the abovementioned alternatives and their consequences Table 1 is demonstrated. 
Table 1. Potential consequences of the change of absolute consumption level from time period $t$ to $t+1$

\begin{tabular}{|c|c|c|c|}
\hline $\begin{array}{c}\text { Change of absolute } \\
\text { consumption level } \\
\text { from time period } t \text { to } \\
t+1 \\
\left(c_{i_{t+1 r}}-c_{i_{t_{r}}}\right)\end{array}$ & $\begin{array}{l}\text { Change of financial } \\
\text { position from time } \\
\text { period } t \text { to } t+1\end{array}$ & $\begin{array}{l}\text { Change of real } \\
\text { consumer utility from } \\
\text { time period } t \text { to } t+1 \\
\quad\left(U_{i_{t+1_{r}}}-U_{i_{t_{r}}}\right)\end{array}$ & $\begin{array}{l}\text { Interpretation of } \\
\text { consequences }\end{array}$ \\
\hline \multirow[b]{3}{*}{$\begin{array}{c}\text { increase } \\
(+)\end{array}$} & \multirow[b]{3}{*}{ weaken } & increase & $\begin{array}{l}\text { the investment into the } \\
\text { additional absolute } \\
\text { consumption is } \\
\text { recovered, improving } \\
\text { relative position }\end{array}$ \\
\hline & & unchangeable & $\begin{array}{c}\text { sustaining social } \\
\text { standing }\end{array}$ \\
\hline & & decrease & $\begin{array}{l}\text { weakened financial } \\
\text { position due to sunk } \\
\text { investment into the } \\
\text { additional absolute } \\
\text { consumption and } \\
\text { underestimation of } \\
\text { others' absolute } \\
\text { consumption, lower } \\
\text { relative position }\end{array}$ \\
\hline \multirow{3}{*}{$\begin{array}{l}\text { unchangeable } \\
(0)\end{array}$} & \multirow{3}{*}{ unchangeable } & increase & $\begin{array}{l}\text { improving relative } \\
\text { standing beside stable } \\
\text { financial position due } \\
\text { to others' lower } \\
\text { absolute consumption }\end{array}$ \\
\hline & & unchangeable & $\begin{array}{l}\text { stable consumption } \\
\text { circumstances }\end{array}$ \\
\hline & & decrease & $\begin{array}{c}\text { lower relative } \\
\text { consumption and } \\
\text { social standing due to } \\
\text { incorrect expectations }\end{array}$ \\
\hline \multirow{3}{*}{$\begin{array}{c}\text { decrease } \\
(-)\end{array}$} & \multirow{3}{*}{ strengthen } & increase & $\begin{array}{l}\text { improving relative } \\
\text { standing due to others' } \\
\text { greater decrease in } \\
\text { absolute consumption } \\
\text { beside strengthen } \\
\text { financial position }\end{array}$ \\
\hline & & unchangeable & $\begin{array}{l}\text { stable relative position } \\
\text { beside strengthen } \\
\text { financial position }\end{array}$ \\
\hline & & decrease & $\begin{array}{c}\text { lower relative position } \\
\text { due to incorrect } \\
\text { expectations }\end{array}$ \\
\hline
\end{tabular}

Source: own compilation 


\subsection{Cases to illustrate uncertain outcomes when relative consumption does matter}

In this section, the above-described relations and explanations are illustrated with a numerical example. Let us assume that individual $i$ can determine the level of $U_{i_{t_{r}}}, U_{i_{t+1} e}$ and $U_{i_{t+1}}$. We assume that individual $i$ compares himself to 10 neighbours. Calculations are conducted both for difference and ratio comparison. In each time period, all the individuals choose an absolute consumption level between 0 and 100. The values of parameter $\beta_{i j}$ and $\gamma_{i j}$ are equivalent in $U_{i_{t_{r}}}, U_{i_{t+1} e}$ and $U_{i_{t+1} r}$. Two different expectations are studied. In the case of expectation 1 , it is rational for individual $i$ to increase his absolute consumption level according to his expectations about others' future absolute consumption level to achieve a higher relative position. In the case of expectation 2 , he decides based on his expectations about neighbours' future absolute consumption level to decrease his absolute consumption level by a certain degree since he believes lagging behind can also be avoided by a lower consumption level. Further, three different potential outcomes (case 1,2 and 3) are generated to both different and ratio comparison since others' future absolute consumption is uncertain. Thus, it can be studied how various choices of others influence individual $i$ 's real utility level in time period $t+1$.

Table 2 and 4 show the values of the parameters and the variables for expectation 1 and 2 , separately. Since the analysis focuses on how neighbours' real absolute consumption levels in time period $t+1$ influence individual $i$ 's real consumer utility level and how high $U_{i_{t+1}}$ is compared to $U_{i_{t_{r}}}$ and $U_{i_{t+1} e}$, the values of $c_{i_{t-1 r}}, c_{i_{t_{r}}}, c_{j_{t-1 r}}, c_{j_{t_{r}}}, \alpha, \beta_{i j}$ and $\gamma_{i j}$ are the same during the study of expectation 1 and 2. Those are randomly generated in their domains. According to expectation 1, individual $i$ expects an increase on average in others' absolute consumption from time period $t$ to $t+1$. Three potential outcomes are studied regarding the change in neighbours' real consumption level. Case 1 reflects a moderate increase on average in their absolute consumption. According to case 2, the average rise of consumption level in the reference group is more significant, and case 3 illustrates a still stronger increase. According to expectation 2, individual $i$ expects a decrease on average in neighbours' absolute consumption from time period $t$ to $t+1$. Case 1 demonstrates a significant decrease on average in their absolute consumption. Case 2 shows a moderate decline, while case 3 illustrates only a small decrease on average in neighbours' absolute consumption. Table 3 and 5 indicate individual $i$ 's current real, expected and potential future consumer utility levels for expectation 1 and 2, separately ${ }^{9}$. Their values are calculated based on functions (1), (2), (5), (6), (7) and (8), and the values of Table 2 and 4.

\footnotetext{
${ }^{9}$ Grey cells indicate the variables and their values which are various due to individual $i$ 's expectations or others' uncertain choices.
} 
Table 2. The values of the parameters and the variables of the utility functions in the case of expectation 1

\begin{tabular}{|c|c|c|c|c|c|c|c|c|c|c|c|}
\hline$c_{i_{t-1}}$ & $c_{i_{t_{r}}}$ & $j$ & $c_{\boldsymbol{j}_{t-1}}$ & $c_{\boldsymbol{j}_{t_{r}}}$ & $c_{\boldsymbol{j}_{t+1_{e}}}$ & & $\boldsymbol{c}_{\boldsymbol{j}_{\boldsymbol{t}+\mathbf{1}_{r}}}$ & & $\alpha$ & $\boldsymbol{\beta}_{i j}$ & $\gamma_{i j}$ \\
\hline 52 & 68 & & & & & $\begin{array}{c}\text { Case } \\
1\end{array}$ & $\begin{array}{c}\text { Case } \\
2\end{array}$ & $\begin{array}{c}\text { Case } \\
3\end{array}$ & 1 & 0.7 & 0.6 \\
\hline & & 1 & 84 & 87 & 84 & 82 & 85 & 96 & & 0.6 & 0.5 \\
\hline & & 2 & 45 & 39 & 42 & 43 & 36 & 51 & & 0.3 & 0.7 \\
\hline & & 3 & 67 & 54 & 63 & 59 & 59 & 52 & & 0.8 & 0.4 \\
\hline & & 4 & 73 & 91 & 93 & 92 & 89 & 95 & & 0.7 & 0.8 \\
\hline & & 5 & 42 & 67 & 72 & 74 & 79 & 78 & & 0.2 & 0.5 \\
\hline & & 6 & 45 & 43 & 45 & 37 & 41 & 49 & & 0.9 & 0.6 \\
\hline & & 7 & 35 & 29 & 34 & 30 & 39 & 41 & & 0.6 & 0.4 \\
\hline & & 8 & 23 & 34 & 41 & 39 & 41 & 45 & & 0.5 & 0.6 \\
\hline & & 9 & 53 & 47 & 59 & 55 & 55 & 63 & & 0.8 & 0.7 \\
\hline & & 10 & 45 & 63 & 67 & 68 & 77 & 79 & & 0.6 & 0.5 \\
\hline
\end{tabular}

Source: own data

Table 3. Current utility, future absolute consumption and potential future utilities in the case of expectation 1

\begin{tabular}{llcc}
\hline & & Difference comparison & Ratio comparison \\
\hline & $\boldsymbol{U}_{\boldsymbol{i}_{\boldsymbol{t}}}$ & 177.4 & 18.35 \\
\hline & $\boldsymbol{c}_{\boldsymbol{i}_{\boldsymbol{t}+\boldsymbol{1}_{\boldsymbol{r}}}}$ & 76 & 82 \\
\hline & $\boldsymbol{U}_{\boldsymbol{i}_{\boldsymbol{t}+\boldsymbol{1}_{\boldsymbol{e}}}}$ & 213.1 & 19.95 \\
\hline Case 1 & $\boldsymbol{U}_{\boldsymbol{i}_{\boldsymbol{t}+\boldsymbol{r}}}$ & 222.1 & 20.42 \\
\hline Case 2 & $\boldsymbol{U}_{\boldsymbol{i}_{\boldsymbol{t}+\boldsymbol{1}_{\boldsymbol{r}}}}$ & 205.8 & 19.81 \\
\hline Case 3 & $\boldsymbol{U}_{\boldsymbol{i}_{\boldsymbol{t}+\boldsymbol{r}}}$ & 175.7 & 18.97 \\
\hline
\end{tabular}

Source: own compilation

For expectation 1, the value of $U_{i_{t_{r}}}$ is determined both for difference and ratio comparison since each variable is known. As individual $i$ strives to improve or at least sustain his utility derived from relative consumption over time, that is, $U_{i_{t_{r}}} \leq U_{i_{t+1} e}$, in the case of difference comparison, he has to consume at least 74 in time period $t+1$ by taking into account his neighbours' expected absolute consumption $\left(c_{j_{t+1} e}\right)$ so that this relation can be valid. Let us assume that he decides to consume a bit more than the minimum required. Thus, $c_{i_{t+1 r}}=76$ and $U_{i_{t+1} e}=213.1$. If others' absolute consumption level in time period $t+1$ is realised according to case 1 that reflects a moderate increase on average in their absolute consumption, $U_{i_{t_{r}}}<U_{i_{t+1} e}<U_{i_{t+1}}$ is valid that is demonstrated by Graph 1a. This relation is the most beneficial for individual $i$. If case 2 is realised, $U_{i_{t_{r}}}<U_{i_{t+1 r}}<U_{i_{t+1 e}}$ is valid, that reflects individual $i$ has improved his position compared to the previous period but by less amount, than he expected. Case 3 is the worst outcome for individual $i$ since his real utility level in time period $t+1$ is lower than in time period $t$ which is presented by Graph 1c.

When ratio comparison occurs, individual $i$ has to consume at least 77 in time period $t+1$ by taking into account his neighbours' expected absolute consumption $\left(c_{j_{t+1} e}\right)$ so that $U_{i_{t_{r}}} \leq U_{i_{t+1_{e}}}$ can be valid. Let us assume again that he consumes a bit more than the minimum required. Thus, $c_{i_{t+1 r}}=82$ and $U_{i_{t+1 e}}=19,95$. The same utility relations arise when case 1 
and 2 are realised as when difference comparison happens. However, when case 3 is attained, $U_{i_{t_{r}}}<U_{i_{t+1}}<U_{i_{t+1 e}}$ is valid, that is due to the relatively higher additional absolute consumption level in time period $t+1$ compared to difference comparison.

The findings suggest that when an individual expects an increase on average in others' absolute consumption but he underestimates the average increase in the consumption of his reference group, his real utility level derived from relative consumption is lower than the expected one, or even lower than the current real utility level. Thus, growing absolute consumption level does not necessarily results in higher relative consumption and investments on positional goods can lead to lower social standing.

In the following, let us see the situation when individual $i$ expects neighbours' absolute consumption level decreases from time period $t$ to $t+1$ (expectation 2). Table 4 differs from Table 2 only in the values of $c_{j_{t+1}}$ and $c_{j_{t+1}}$.

Table 4. The values of the parameters and the variables of the utility functions in the case of expectation 2

\begin{tabular}{|c|c|c|c|c|c|c|c|c|c|c|c|}
\hline$c_{i_{t-1}}$ & $\boldsymbol{c}_{\boldsymbol{i}_{\boldsymbol{t}_{r}}}$ & $j$ & $c_{j_{t-1}}$ & $\boldsymbol{c}_{\boldsymbol{j}_{\boldsymbol{t}_{r}}}$ & $c_{j_{t+1}}$ & & $c_{\boldsymbol{j}_{t+1 \mathbf{1}}}$ & & $\alpha$ & $\boldsymbol{\beta}_{i j}$ & $\gamma_{i j}$ \\
\hline 52 & 68 & & & & & $\begin{array}{c}\text { Case } \\
1\end{array}$ & $\begin{array}{c}\text { Case } \\
2\end{array}$ & $\begin{array}{c}\text { Case } \\
3\end{array}$ & 1 & 0.7 & 0.6 \\
\hline & & 1 & 84 & 87 & 72 & 71 & 75 & 83 & & 0.6 & 0.5 \\
\hline & & 2 & 45 & 39 & 23 & 22 & 28 & 41 & & 0.3 & 0.7 \\
\hline & & 3 & 67 & 54 & 41 & 45 & 43 & 52 & & 0.8 & 0.4 \\
\hline & & 4 & 73 & 91 & 74 & 72 & 74 & 87 & & 0.7 & 0.8 \\
\hline & & 5 & 42 & 67 & 51 & 50 & 52 & 63 & & 0.2 & 0.5 \\
\hline & & 6 & 45 & 43 & 27 & 29 & 24 & 41 & & 0.9 & 0.6 \\
\hline & & 7 & 35 & 29 & 17 & 16 & 21 & 21 & & 0.6 & 0.4 \\
\hline & & 8 & 23 & 34 & 17 & 17 & 19 & 32 & & 0.5 & 0.6 \\
\hline & & 9 & 53 & 47 & 32 & 30 & 30 & 42 & & 0.8 & 0.7 \\
\hline & & 10 & 45 & 63 & 51 & 46 & 48 & 61 & & 0.6 & 0.5 \\
\hline
\end{tabular}

Source: own data

Table 5. Current utility, future absolute consumption and potential future utilities in the case of expectation 2

\begin{tabular}{llcc}
\hline & & Difference comparison & Ratio comparison \\
\hline & $\boldsymbol{U}_{\boldsymbol{i}_{t_{r}}}$ & 177.4 & 18.35 \\
\hline & $\boldsymbol{c}_{\boldsymbol{i}_{t+1_{r}}}$ & 66 & 66 \\
\hline & $\boldsymbol{U}_{\boldsymbol{i}_{t+1_{\boldsymbol{e}}}}$ & 200 & 21.57 \\
\hline Case 1 & $\boldsymbol{U}_{\boldsymbol{i}_{t+1_{r}}}$ & 207.9 & 22.02 \\
\hline Case 2 & $\boldsymbol{U}_{\boldsymbol{i}_{t+1_{r}}}$ & 192.8 & 20.48 \\
\hline Case 3 & $\boldsymbol{U}_{\boldsymbol{i}_{t+1_{r}}}$ & 131 & 18.01 \\
\hline
\end{tabular}

Source: own compilation

The value of $U_{i_{t_{r}}}$ is equivalent in Table 3 and 5 as the initial situation is the same. However, individual $i$ expects his neighbours' absolute consumption level $\left(c_{j_{t+1} e}\right)$ will be lower in time period $t+1$ compared to $t$. By taking it into consideration, individual $i$ has to consume minimum 65 in time period $t+1$ in the case of difference comparison to sustain his utility derived from relative consumption. The minimum required is 56 in the case of ratio comparison. 
Let us assume that $c_{i_{t+1 r}}=66$ in the case of both difference and ratio comparison, that is, individual $i$ decreases his absolute consumption level from time period $t$ to $t+1$ but consumes more than the minimum required. Case 1 reflects others' absolute consumption level has decreased significantly from time period $t$ to $t+1$, by a greater amount on average as it has been expected, and thus $U_{i_{t_{r}}}<U_{i_{t+1}}<U_{i_{t+1}}$ for both difference and ratio comparison. Case 2 expresses a moderate while case 3 a small decrease on average in neighbours' absolute consumption, consequently $U_{i_{t_{r}}}<U_{i_{t+1 r}}<U_{i_{t+1} e}$ and $U_{i_{t+1 r}}<U_{i_{t_{r}}}<U_{i_{t+1_{e}}}$ are valid, separately. However, it is important to realise and point out that in case $3, U_{i_{t+1} r}$ is relatively much lower compared to $U_{i_{t_{r}}}$ and $U_{i_{t+1}}$ in case of difference comparison than ratio comparison. This means that the form of social comparison does matter.

According to the results, when an individual expects a decrease on average in others' absolute consumption but he overestimates the average decrease in neighbours' consumption, his real utility level is lower than the expected one, or even lower than the current real utility level. However, a lower absolute consumption level can result in a high relative consumption when the abovementioned misprediction does not occur. In a recession, when people tend to spend less on travelling and holidays and an individual believes that his friends and colleagues would decrease their expenditures on these activities significantly, but he realises through social media that not, his relative consumption and the derived enjoyment decreases.

Finally, if we compare the values of Table 3 and 5, we conclude that through lower absolute consumption level individual $i$ can realise higher utility derived from relative consumption. In other words, higher absolute consumption level not necessarily provides higher consumer utility when positional concerns does matter. This means at the same time that neighbours' uncertain future absolute consumption level can result in both higher and lower social standing.

\section{Conclusion}

An individual's consumer utility depends not only on his own absolute consumption level but how much he consumes relative to others, and what importance he attaches to their consumption. It reflects that relative consumption is essential for individuals as positional concerns matter. Both emotional and rational reasons contribute to the striving after a higher social position. However, relative consumption can also be explained by social comparison theory (Festinger, 1954). Nowadays, the social comparison has become more intensive due to cultural and communication technological environments. In consequence of the power of social media, less visible goods and experimental purchase have become more observable by others, that is, relative consumption is not restricted to physical goods any more (Yang \& Mattila, 2017; Bronner \& de Hoog, 2018). Social comparison can occur in a cardinal or ordinal way (Bilancini \& Boncinelli, 2008), and the subjective social status perceived by an individual is critical in his consumer decision-making and self-assessment (Bucciol et al., 2015). Both social and financial reference points influence relative consumption (Lu et al., 2015), and thus, the utility level derived from it. As an individual usually strives for a higher social position, expectations about others' future consumption have a relevant role in his consumer decision making, mainly because those are uncertain. As this is an uncertain intertemporal choice, an individual cannot be sure that the investments on positional goods will be returned, that is, he can achieve a higher relative consumption and social standing, and an increase in his consumer utility level.

The model presented reflects the dynamics and intertemporal effects of relative consumption concerning consumer utility. It describes by applying theoretical comparative 
analysis, how an individual's consumer utility derived from relative consumption can change when his social reference points' future absolute consumption level is uncertain. When an individual wants to improve or at least sustain his relative position, he has to take into account and estimate the future absolute consumption level of the persons belonging to his reference group. However, the neighbours' future consumption is usually uncertain. Consequently, when an individual expects an increase on average in others' absolute consumption, but the increase is more significant than he expected, the individual's real utility level derived from relative consumption is lower than the expected one, or even lower than the current real utility level in case of a power increase. Further, when an individual expects a decrease on average in others' absolute consumption, but the decrease is less significant as he expected, the individual's real utility level is lower than the expected one, or even lower than the current real utility level in case of only a small decrease. Thus, the return on investment on positional goods can result in a higher or lower social standing that is also related to an individual's financial position.

The model also points out that an individual who strives for higher social standing cannot be a maximiser but a satisficer if social comparison occurs in a cardinal sense. The outcome of the consumer decision and the beneficial or unfavourable change of the utility level also depend on whether difference or ratio comparison occurs. Thus, all in all, the features of social comparison do matter in relative consumption.

\section{Acknowledgement}

This research was supported by the János Bolyai Research Scholarship of the Hungarian Academy of Sciences.

\section{References}

Akerlof, G. A. (1997). Social distance and social decisions. Econometrica, 65(5), 1005-1027. https://doi.org/10.2307/2171877

Alicke, M. D. (2007). In defense of social comparison. Revue Internationale de Psychologie Sociale, 20(1), 12-29.

Alpizar, F., Carlsson, F., \& Johansson-Stenman, O. (2005). How much do we care about absolute versus relative income and consumption?. Journal of Economic Behavior \& Organization, 56(3), 405-421. https://doi.org/10.1016/j.jebo.2002.10.007

Aronsson, T., \& Johansson-Stenman, O. (2014). Positional preferences in time and space: Optimal income taxation with dynamic social comparisons. Journal of Economic Behavior \& Organization, 101, 1-23. https://doi.org/10.1016/j.jebo.2014.01.004

Ball, S., Eckel, C., Grossman, P. J., \& Zame, W. (2001). Status in markets. Quarterly Journal of Economics, 116(1), 161-188. https://doi.org/10.1162/003355301556374

Bilancini, E., \& Boncinelli, L. (2008). Ordinal vs cardinal status: Two examples. Economics Letters, 101(1), 17-19. https://doi.org/10.1016/j.econlet.2008.03.027

Birdal, M., \& Ongan, H. (2016). Why do we care about having more than others? Socioeconomic determinants of positional concerns in different domains. Social Indicators Research, 126(2), 727-738. https://doi.org/10.1007/s11205-015-0914-9

Brekke, K. A., Howarth, R. B., \& Nyborg, K. (2003). Status-seeking and material affluence: Evaluating the Hirsch hypothesis. Ecological Economics, 45(1), 29-39. https://doi.org/10.1016/s0921-8009(02)00262-8

Bronner, F., \& de Hoog, R. (2018). Conspicuous consumption and the rising importance of experimental purchases. International Journal of Market Research, 60(1), 88-103. https://doi.org/10.1177/1470785317744667 
Bucciol, A., Cavasso, B., \& Zarri, L. (2015). Social status and personality traits. Journal of Economic Psychology, 51, 245-260. https://doi.org/10.1016/j.joep.2015.10.002

Carlsson, F., Johansson-Stenman, O., \& Martinsson, P. (2007). Do you enjoy having more than others? Survey evidence of positional goods. Economica, 74(296), 586-598. https://doi.org/10.1111/j.1468-0335.2006.00571.x

Celse, J., Galia, F., \& Max, S. (2017). Are (negative) emotions to blame for being positional? An experimental investigation of the impact of emotional states on status preferences. Journal of Behavioural and Experimental Economics, 67, 122-130. https://doi.org/10.1016/j.socec.2016.12.004

Clark, A. E., \& Oswald, A. J. (1998). Comparison-concave utility and following behavior in social and economic settings. Journal of Public Economics, 70(1), 133-155. https://doi.org/10.1016/s0047-2727(98)00064-4

Duesenberry, J. S. (1949). Income, Saving and the Theory of Consumer Behavior. Cambridge, MA: Harvard University Press.

Festinger, L. (1954). A theory of social comparison processes. Human Relation, 7(2), 117-140. https://doi.org/10.1177/001872675400700202

Frank, R. H. (1985a). Choosing the Right Pond: Human Behavior and the Quest for Status. New York: Oxford University Press.

Frank, R. H. (1985b). The demand for unobservable and other nonpositional goods. American Economic Review, 75(1), 101-116.

Frank, R. H. (2005). Positional externalities cause large and preventable welfare losses. American Economic Review, 137-141. https://doi.org/10.1257/000282805774670392

Galbraith, J. K. (1958). The Affluent Society. Boston, MA: Houghton Mifflin.

Garcia, S. M., Tor, A., \& Schiff, T. M. (2013). The psychology of competition: A social comparison perspective. Perspectives on Psychological Science, 8(6), 634-650. https://doi.org/10.1177/1745691613504114

Goerke, L. (2013). Relative consumption and tax evasion. Journal of Economic Behavior \& Organization, 87, 52-65. https://doi.org/10.1016/j.jebo.2012.12.028

Grolleau, G., \& Saïd, S. (2008). Do you prefer having more or more than others? Survey evidence on positional concerns in France. Journal of Economic Issues, 42(4), 11451158. https://doi.org/10.1080/00213624.2008.11507206

Grolleau, G., Mzoughi, N., \& Saïd, S. (2012). Do you believe that others are more positional than you? Results from an empirical survey on positional concerns in France. Journal of Socio-Economics, 41(1), 48-54. https://doi.org/10.1016/j.socec.2011.10.001

Heath, C., Larrick, R. P., \& Wu, G. (1999). Goals as reference points. Cognitive Psychology, 38(1), 79-109. https://doi.org/10.1006/cogp.1998.0708

Hirsch, F. (1976). Social Limits to Growth. Cambridge, MA: Harvard University Press.

Hopkins, E., \& Kornienko, T. (2004). Running to keep in the same place: Consumer choice as a game of status. American Economic Review, 94(4), 1085-1107. https://doi.org/10.1257/0002828042002705

Hopkins, E., \& Kornienko, T. (2009). Status, affluence, and inequality: Rank-based comparisons in games of status. Games and Economic Behavior, 67(2), 552-558. https://doi:10.1016/j.geb.2009.02.004

Kahneman, D. (1992). Reference points, anchors, norms, and mixed feelings. Organizational Behavior and Human Decision Processes, 51(2), 296-312. https://doi.org/10.1016/07495978(92)90015-y

Kahneman, D., \& Tversky, A. (1984). Choices, values, and frames. American Psychologist, 39(4), 341-350. https://doi.org/10.1037//0003-066x.39.4.341 
Keynes, J. M. (1936/1996). The General Theory of Employment, Interest and Money. London: Macmillan; New York: University of Chicago Press.

Knight, F. H. (1921). Risk, Uncertainty, and Profit. Boston, MA: Hart, Schaffner \& MarxHoughton Mifflin Co.

Koop, G. J., \& Johnson, J. G. (2012). The use of multiple reference points in risky decision making. Journal of Behavioral Decision Making, 25(1), 49-62. https://doi.org/10.1002/bdm.713

Köszegi, B., \& Rabin, M. (2009). Reference-dependent consumption plans. American Economic Review, 99(3), 909-936. https://doi.org/10.1257/aer.99.3.909

Leguizamon, S. (2016). Who cares about relative status? A quantile approach to consumption of relative house size. Applied Economics Letters, 23(5), 307-312. https://doi.org/10.1080/13504851.2015.1066485

Lu, J., Xie, X., Wang, M., \& Tang, X. (2015). Double reference points: The effects of social and financial reference points on decisions under risk. Journal of Behavioral Decision Making, 28(5), 451-463. https://doi.org/10.1002/bdm.1862

Ordóñez, L. D., Connolly, T., \& Coughlan, R. (2000). Multiple reference points in satisfaction and fairness assessment. Journal of Behavioral Decision Making, 13(3), 329-344. https://doi.org/10.1002/1099-0771(200007/09)13:3<329::aid-bdm356>3.0.co;2-q

Pigou, A. C. (1903). Some remarks on utility. The Economic Journal, 13(49), 58-68. https://doi.org/10.2307/2956866

Pigou, A. C. (1913). The interdependence of different sources of demand and supply in a market. The Economic Journal, 23(89), 19-24. https://doi.org/10.2307/2222206

Rayo, L., \& Becker, G. S. (2007). Evolutionary efficiency and happiness. Journal of Political Economy, 115(2), 302-337. https://doi.org/10.1086/516737

Rohde, I. M. T., \& Rohde, K. I. M. (2011). Risk attitudes in a social context. Journal of Risk and Uncertainty, 43(3), 205-225. https://doi.org/10.1007/s11166-011-9127-z

Rustichini, A., DeYoung, C. G., Anderson, J. E., \& Burks, S. V. (2016). Toward the integration of personality theory and decision theory in explaining economic behavior: An experimental investigation. Journal of Behavioral and Experimental Economics, 64, 122 137. https://doi.org/10.1016/j.socec.2016.04.019

Schwartz, B., Ward, A., Monterosso, J., Lyubomirsky, S., White, K., \& Lehman, D. R. (2002). Maximizing versus satisficing: happiness is a matter of choice. Journal of Personality and Social Psychology, 83(5), 1178-1197. https://doi.org/10.1037//0022-3514.83.5.1178

Scitovsky, T. (1976). The Joyless Economy: The Psychology of Human Satisfaction. New York: Oxford University Press.

Simon, H. A. (1956). Rational choice and the structure of the environment. Psychological Review, 63(2), 129-138. https://doi.org/10.1037/h0042769

Smith, A. (1776/1976). An Inquiry into the Nature and Causes of the Wealth of Nations. Chicago: University of Chicago Press.

Solnick, S. J., \& Hemenway, D. (1998). Is more always better?: A survey on positional concerns. Journal of Economic Behavior \& Organization, 37(3), 373-383. https://doi.org/10.1016/s0167-2681(98)00089-4

Solnick, S. J., \& Hemenway, D. (2005). Are positional concerns stronger in some domains than in others? American Economic Review, 95(2), 147-151. https://doi.org/10.1257/000282805774669925

Solnick, S. J., Hong, L., \& Hemenway, D. (2007). Positional goods in the United States and China. The Journal of Socio-Economics, 36(4), 537-545. https://doi.org/10.1016/j.socec.2006.12.012

Van de Ven, N., Zeelenberg, M., \& Pieters, R. (2009). Leveling up and down: The experiences of benign and malicious envy. Emotion, 9(3), 419-429. https://doi.org/10.1037/a0015669 
Veblen, T. (1899/1979). The Theory of the Leisure Class. Harmondsworth: Penguin Books.

Wang, H., Cheng, Z., \& Smyth, R. (2019). Consumption and happiness. The Journal of Development Studies, 55(1), 120-136. https://doi.org/10.1080/00220388.2017.1371294

Wang, X. T., \& Johnson, J. G. (2012). A tri-reference point theory of decision making under risk. Journal of Experimental Psychology: General, 141(4), 743-756. https://doi.org/10.1037/a0027415

Weaver, K., Daniloski, K., Schwarz, N., \& Cottone, K. (2015). The role of social comparison for maximizers and satisficers: Wanting the best or wanting to be the best? Journal of Consumer Psychology, 25(3), 372-388. https://doi.org/10.1016/j.jcps.2014.10.003

Yang, W., \& Mattila, A. S. (2017). The impact of status seeking on consumers' word of mouth and product preference - A comparison between luxury hospitality services and luxury goods. Journal of Hospitality \& Tourism Research, 41(1), 3-22. https://doi.org/10.1177/1096348013515920 